A Knowledge-Based Simulation System

for Construction operations

\author{
Naruo Kano \\ Visiting Professor \\ Stanford University \\ Stanford, CA 94305-4020
}

\begin{abstract}
The author points out that the existing simulation systems cannot represent precisely the ill-structured logic in construction operations without if-then representation. He also discusses the methodologies of system simulation which are based on artificial intelligence methods. The author then presents a prototype system developed of the simulation system, and shows an example of simulation models and the results using the OPS/83 system.

It is concluded that the methodologies described in the paper are indispensable for developing a precise system model of construction operations and, hence, improving them.
\end{abstract}

1. Introduction

The use of system simulations for construction operations began in the $1960 \mathrm{~s}$, and many attempts at basic research, system developments and their implementations have been conducted on this theme.

Construction operations, however, involve few repetitive works under the same conditions except in some parts of highrise building construction, therefore the benefits of simulation are yet to be fully enjoyed in construction sites. In order to meet the social needs for higher productivity and more rapid accomplishment of construction projects, research and development of system simulation techniques are indispensable to support the implementation of new construction methods and the rationalization of the works.

This study is intended to enable accurate modeling of construction operations by applying the methodologies of knowledge engineering for system simulations, and representing the sophisticated logics of the construction process in expressions of the if-then rules.

2. System Simulation for Construction operations

2.1. General Purpose Simulation Languages

Simulation is usually achieved by using a general purpose simulation language. As the modeling of activities requires handling of the start and completion of each activity as discrete events, a discrete simulation language such as GPSS or SLAM is often used. There is the problem, however, that modeling the sophisticated process in any such general purpose simulation language requires much manpower and time. Further, because construction operations have the characteristic that the working conditions vary considerably from site to site, a simulation model needs to be prepared anew for each construction project, hence the manpower requirement of modeling substantially affects the 
justifiability of simulation.

2.2. Simulation Systems for Construction operations

With a view to efficient simulation of construction operations, studies were actively carried out on the use of problem-oriented systems. As a result, many simulation systems were developed for use in construction management and project management.

A.A.B.Pritsker (1963) developed GERT ${ }^{1}$ ) for process simulation under uncertain conditions on the basis of flow theory, and demonstrated the effectiveness of the problemoriented approach. D.W.Halpin et al. (1972) classified construgfion operations into several types, and developed CYCLONE which simulates them as represented, in a process chart. This was further developed into SIGHT), a real-time simulation system which enables models to be visually formulated. Kanaiwa (1981) developed a construction model visualizing the relationships between activities and resources and their simulation system known as SIMC0 4 . The author (1986) also proposed a method to express resources, activities, spaces and building elements of construction work in a graphic model, and developed a prototype system called GRAPSS ${ }^{\text {I }}$.

These simulation systems, however, are still insufficient to faithfully express all the logics required for construction operations.

3. Simulation with Knowledge Models

3.1. Needs for Knowledge-Modeling of Activities

The following two examples are readily conceivable as construction operations which are difficult to express by using available models.

(1) Rules for the start of an activity

Main requisites to the start of an activity include the completion of preceding activities, availability of necessary resources and availability of the required space. Yet, model representation of various constraints on an actual activity should also take into account many other conditions, including such limiting factors to the work environment as the weather and temperature and the effects of the progress of other activities. Where, for instance, it is prescribed that formwork should be immediately interrupted if it begins to rain and be replaced by indoor preparation works, the representation of this requirement with any existing simulation system will need a very complex program.

(2) Allocation of workers in activities

In simulating a process comprising more than one activity, the size of the crew in each activity is determined to be optimal for productivity and safety. If the process is delayed by an uncontrollable factor, however, an attempt is usually made to make up for the delay and complete the process by its deadline by transferring workers engaged in less urgent activities to the delayed one. This logic requires constant monitoring of the progress of activities to provide for proper allocation of crews. It is not easy to model this loglc with any existing simulation system. 
3.2. Concept of Knowledge-Based Simulation

Knowledge-Based simulation uses a program language based on the if-then rule in simulating construction operations. It is intended to simulate not only the progress of work, but also plans related activities and their changes by applying the if-then rule.

Unlike the conventional methods of simulating construction operations which place emphasis on the graphic representation, the knowledge-based simulation gives priority to the accurate modeling of work logics, so that there is no consideration given to graphic representation of its models. However, as visual expression of models has an important bearing on the ease of model formulation, the Process Graph which the author has developed is used only for representing the precedences among activities and the relationships between the activities and resources.

The concept of this simulation is schematically shown in Fig. 1 .

\section{Knowledge-Based Simulation}

4.1. Elements of Modeling

The modeis used for this simulation have been systematized on the basis of two methodologies. One of the models is according to the Process Graph and the other according to the data structure used in the Expert system for planning and scheduling.

Representation of activities requires clear definition of the workers engaged, materials, scaffoldings and equipment used in each activity as well as that of the activities themselves, such as conveyance, processing, assembling and disassembling. Further, in order to represent detailed logics of the process, the constraints which vary from moment to moment with changes in the work environment and the progress of the operations should also be defined. The following four elements were defined.

1) Activity: This refers to every activity related to construction.

2) Substance: Every individual person, physical object or collective concept thereof related to construction is referred to as a substance.

3) Event: Every phenomenon, state or condition related to construction is an event in this context.

4) Space: This concept covers every place, position and point related to construction.

These elements of representation constitute the model of construction operations with the attributes of each element and relationships between the elements as shown Figure 2.

4.2. Representation of Activity

Activities are broadly classified into two types. One does not allow interruption once it is started, while the other can be interrupted while in progress. The former is called the continuous type, and the latter, the discrete type. Main attributes of activities are listed in Table 1. Relationships in construction operations involve all the elements including activity, substance, event and space. 


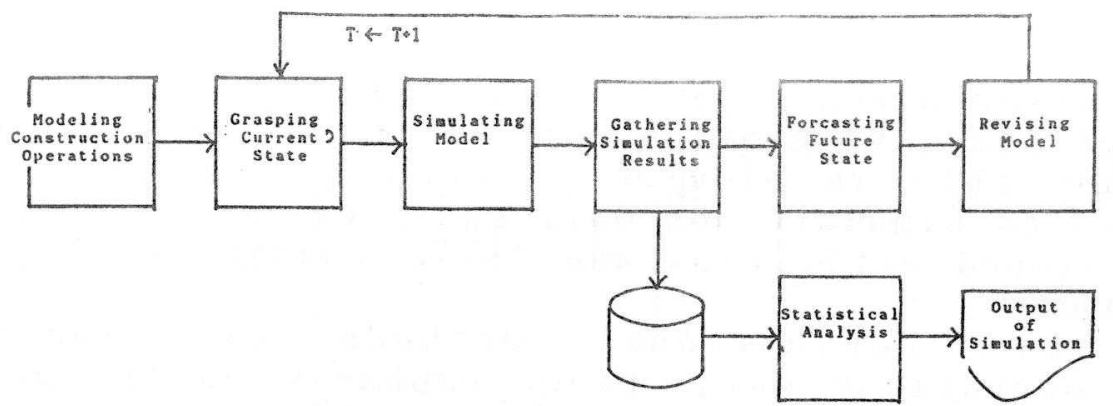

Fig. 1 Concept of Knowledge-Based Simulation

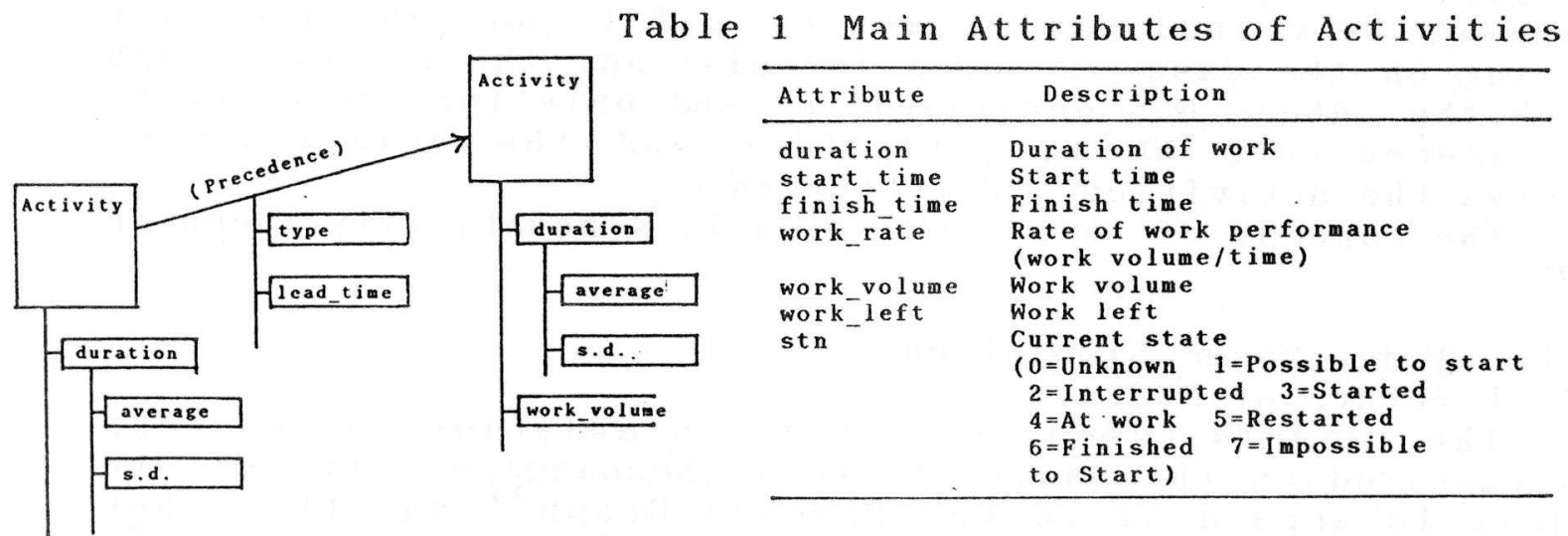

: Element $\longrightarrow$ : Relation $\square$ : Attribute

\section{Fig. 2 Elements, Relationships}

and Attributes in a Model

Table 2 Relationships in Construction operations

\begin{tabular}{|c|c|}
\hline Attribute & Description \\
\hline precede->follow & \\
\hline rel t ype & Type (SS,SF,FS, FF) \\
\hline $\begin{array}{l}\text { lead_time } \\
\text { activated_time }\end{array}$ & $\begin{array}{l}\text { Lead time } \\
\text { Time activated }\end{array}$ \\
\hline control- $-\overline{c o n t r o l e d}$ & \\
\hline $\begin{array}{l}\text { rel_type } \\
\text { lead_time }\end{array}$ & $\begin{array}{l}\text { Type (SS,SF,FS,FF) } \\
\text { Lead time }\end{array}$ \\
\hline $\begin{array}{l}\text { activated_time } \\
\text { used=use }\end{array}$ & Time activated \\
\hline volume & $\begin{array}{l}\text { Required quantity } \\
\text { (Non-consumable input) }\end{array}$ \\
\hline rate & $\begin{array}{l}\text { Required quanticy per work } \\
\text { volume }\end{array}$ \\
\hline $\begin{array}{l}\text { activated time } \\
\text { input } \rightarrow \text { put in }\end{array}$ & Time activated \\
\hline volume & $\begin{array}{l}\text { Required Quantity } \\
\text { (Consuable input) }\end{array}$ \\
\hline rate & $\begin{array}{l}\text { Required quantity per,work } \\
\text { volume }\end{array}$ \\
\hline activated_time & Time $\cdots$ \\
\hline putout $>$ outnnt & 孔upied space capacity \\
\hline$\cdots+1$ & $\begin{array}{l}\text { Occupied space capacity per } \\
\text { work volume }\end{array}$ \\
\hline $\begin{array}{l}\text { activated time } \\
\text { affect }>\text { depend }\end{array}$ & Time activated \\
\hline $\begin{array}{l}\text { lead_time } \\
\text { activated_time } \\
\text { movein->moveout }\end{array}$ & $\begin{array}{l}\text { Lead time for activating } \\
\text { Time astivated }\end{array}$ \\
\hline $\begin{array}{l}\text { start time } \\
\text { finish_time } \\
\text { volume } \\
\text { activity }\end{array}$ & $\begin{array}{l}\text { Start time } \\
\text { Finish time } \\
\text { Moved quantity } \\
\text { Activity name } \\
\end{array}$ \\
\hline
\end{tabular}


Table 2 shows these relationships and their respective attributes.

4.3. Representation of Substance

The concept of substance refers to all individual persons and goods in the work site, and the location and movements of persons and goods in and around the work site are modeled in terms of this element. For some activities, there may be represented a situation in which materials are processed into a section, or a unit of equipment disassembled into a number of parts, which are conveyed by different activities.

4.4. Representation of Event

By representing various situations, phenomena and conditions of activities as individual elements, various constraints on the progress of work can be modeled. If, for instance, there is the constraint that lifting of materials at a certain point cannot be carried out if the wind velocity at the point is more than $10 \mathrm{~m} / \mathrm{sec}$, the event of wind velocity (wind_velocity) in the worksite (space_1) is so defined.

4.5. Representation of Space

Representation space is needed to model the relationships between the spatial positions of substances and events and to simulate the routes of moving the substances.

5. Representation based on If-Then Rules

In the model, the situation of construction work is represented by the four elements explained above and the relationships among these elements, and its details are defined by the attributes of the elements and their mutual relationships. For this reason, rule-based modeling is accomplished by representing relationships among different attributes with the if-then rules and the relationships are actuated at the time of implementing the simulation system. As an example of rules, the relationship between lifting and wind velocity at the site represented below according to an if-then rule.

rule control lifting

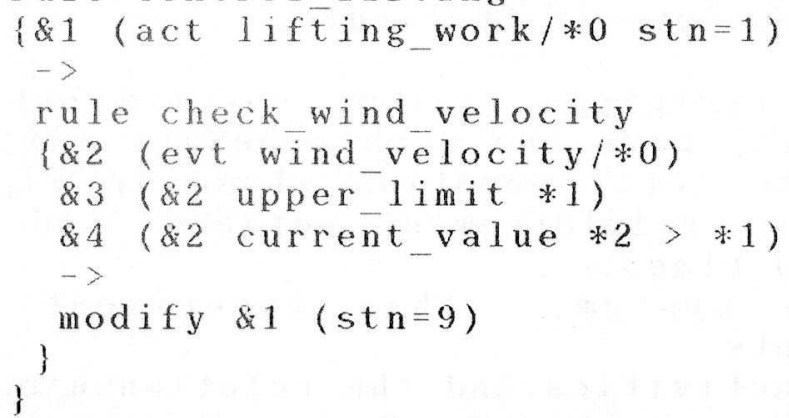

The following explanation may render the meaning of the if-then rule shown above more understandable.

$<$ Rule: Constraint on the start of lifting >

$\{[\& 1]$ If the start of lifting in the space [*0] bas become possible (stn=1),

then, the following will be implemented:

$<$ Rule: Check-up of the wind velocity> 
$\{$ [\&2] If wind velocity data for the space [*0] exist,

[\&3] If the upper limit [*1] of \&2 is available,

[\&4] If the current value [*2] is greater than [*1],

then, the activity of \& 1 will be impossible to start $(\operatorname{stn}=9)$.

)

\}

Precedences among activities and the allocation of resources can all be represented with the if-then rules as shown above. The burden on construction managers formulating the model can be reduced by incorporating in advance, the work logics frequently used into the system as rules.

6. Prototype System for Knowledge-Based Simulation

The system comprises a subsystem for reading the descriptive data and a preprocessing subsystem for linking the rule with the simulation program. The run subsystem for simulation is formulated with a rule-type program and enables sophisticated work logics to be executed.

A afototype system was developed in the 0PS/83 language to assess the feasibility of this methodology. For this purpose, the rule-type data in the simulation model were linked to the main system after being translated into OPS/83 language, and the simulation was carried out by it.

7. Implementation of Knowledge-Based Simulation

7.1. Model of Ground-Assembling of Column Reinforcements The operations mentioned here were the same as theg groundassembling of column reinforcements used in GRAPSS ${ }^{8}$, which is the problem-oriented system the author had developed. The finished state of the ground-assembled column reinforcements is illustrated in Fig. 3. The ground assembling operation consisted of 27 work elements listed in Table 3 .

The part of input data for the system, prepared on the basis of this model, are shown in Table 4. In this trial, two conveyance activities, one for beam hanging hoops and the other for reinforcing bars (a24 and a25), were assumed to be carried out a little earlier than needed, and these requirements were formulated into if-then rules.

7.2. Results of Simulation

Simulation using the prototype system, carried out on the basis of the input data, gave the work schedule and the overall distribution of the total duration shown in Fig. 4 . The simulation assumed two reinforcement workers, and the simulation was iterated 100 times.

Using the prototype system, this experiment has revealed the following points.

1) The precedence of activities and the relationships of input and output of resources in the activities are suitable for representation in a Process Graph.

2) Information concerning the workers to be engaged and the equipment to be used in each activity are more suitable for representation in descriptive data.

3) The use of knowledge-based models makes it possible to simulate logics which are too sophisticated to be 


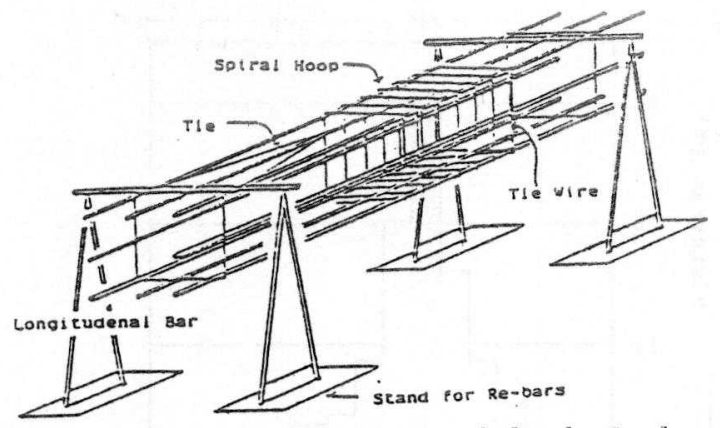

Fig. 3 Ground-Assembled Column Reinforcements in the Finished State

Table 4 Input data

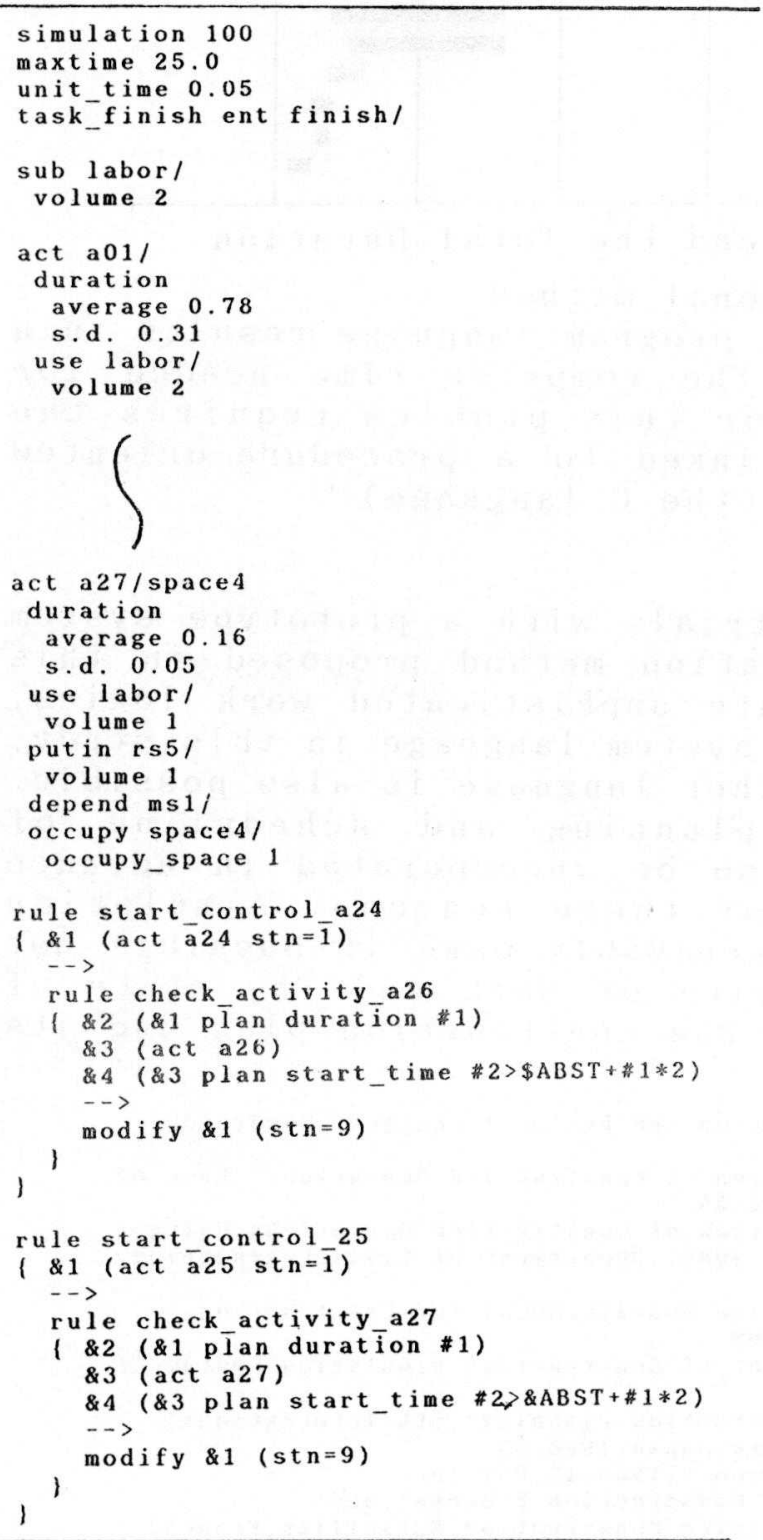

Table 3 Work Elements of GroundAssembled Column Reinforcements

\begin{tabular}{|c|c|c|}
\hline $\begin{array}{l}\text { ID } \\
\text { Code }\end{array}$ & Description & $\begin{array}{l}\text { Workers } \\
\text { (Men) }\end{array}$ \\
\hline A01 & Delivery of stands & 2 \\
\hline A 02 & Delivery and unload of hoop & 1 \\
\hline A03 & $\begin{array}{l}\text { Putting upper } 0-25 \text { bar in } \\
\text { place }\end{array}$ & 2 \\
\hline A 04 & Delivery of upper $D-25$ bar & 1 \\
\hline A 05 & Putting hoop in place & 2 \\
\hline A 06 & Marking & 1 \\
\hline A 07 & Arrangement of hoop & 2 \\
\hline A 08 & Delivery of lower D-25 bar & 1 \\
\hline A 09 & $\begin{array}{l}\text { Arrangement of lower D-25 } \\
\text { bar }\end{array}$ & 2 \\
\hline A 10 & Delivery of D-19 bar & 1 \\
\hline A 11 & Putting hoop in order & 1 \\
\hline A 12 & $\begin{array}{l}\text { Putting upper } 0-25 \text { bar in } \\
\text { order }\end{array}$ & 1 \\
\hline A 13 & $\begin{array}{l}\text { Putting lower D-25 bar in } \\
\text { order }\end{array}$ & 1 \\
\hline A 14 & Arrangement of $\mathrm{D}-19$ bar & 2 \\
\hline A 15 & Binding of $D-25$ bar & 2 \\
\hline A 16 & $\begin{array}{l}\text { Preliminary binding of } \\
\text { right side D-19 bar }\end{array}$ & 2 \\
\hline A 17 & $\begin{array}{l}\text { Preliminary binding of } \\
\text { left side } D-19 \text { bar }\end{array}$ & 2 \\
\hline A 18 & $\begin{array}{l}\text { Binding right side } D-19 \\
\text { bar }\end{array}$ & 1 \\
\hline A 19 & $\begin{array}{l}\text { Binding left side D-19 } \\
\text { bar }\end{array}$ & 1 \\
\hline A 20 & $\begin{array}{l}\text { Preliminary binding of } \\
\text { upper D-19 bar }\end{array}$ & 2 \\
\hline A 21 & $\begin{array}{l}\text { Preliminary binding of } \\
\text { lower D-19 bar }\end{array}$ & 2 \\
\hline A 22 & Binding of upper D-19 bar & 1 \\
\hline A23 & Binding of lower D-19 bar & 1 \\
\hline A 24 & Delivery of tie wires & 1 \\
\hline A25 & Delivery of tie & 1 \\
\hline A 26 & Binding of tie wire & 1 \\
\hline A 27 & Binding of tie & 1 \\
\hline
\end{tabular}




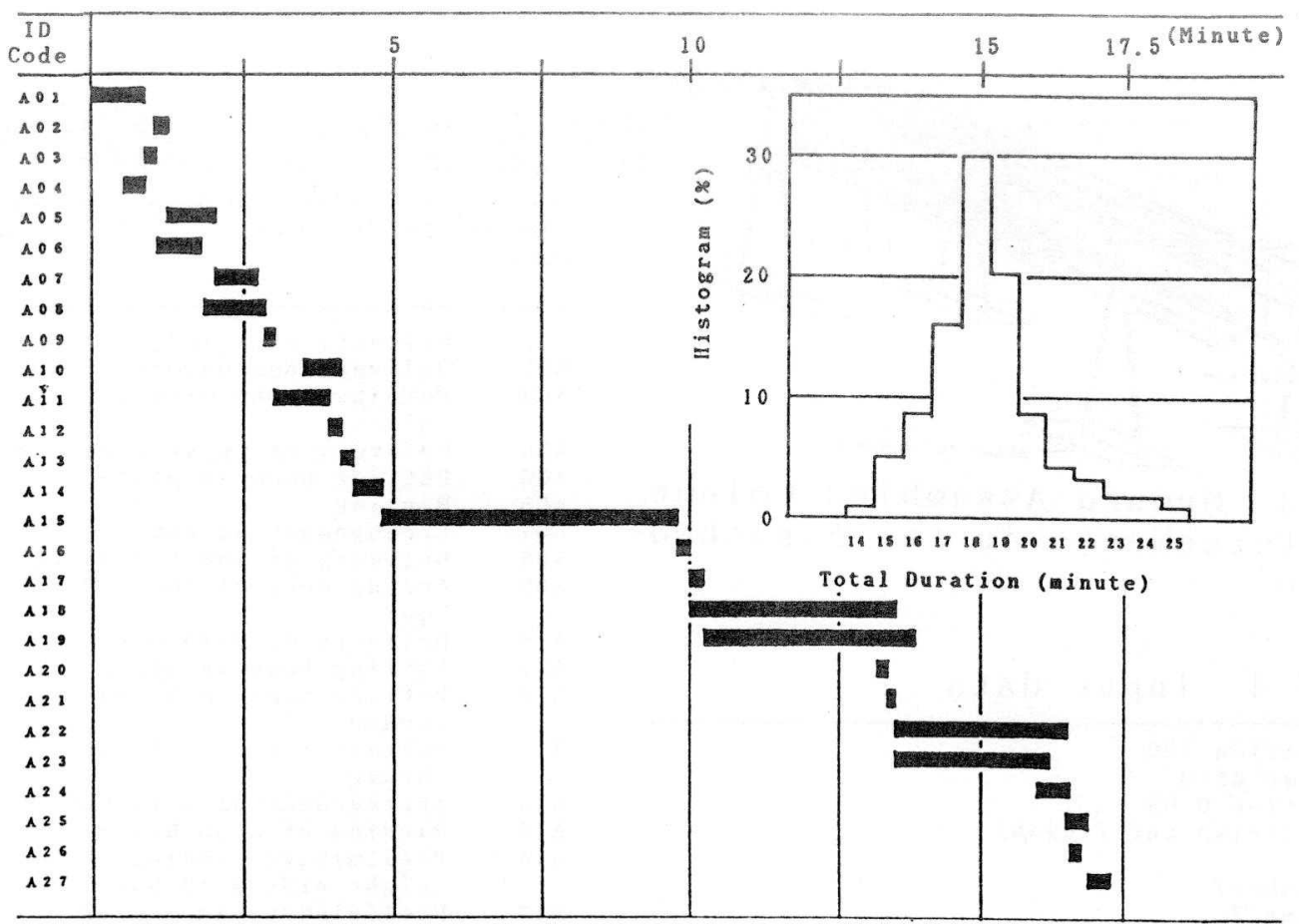

Fig. 4 A Work Schedule and the Total Duration

simulated by any conventional method.

4) The use of a rule-based program language results in a substantial increase in the computer time needed for simulation. Solution for this problem requires the development of system linked to a procedure-oriented program language (such as the C language).

\section{Conclusion}

It has been confirmed by trials with a prototype system that the knowledge-based simulation method proposed in this paper can represent and simulate sophisticated work logics. Whereas OPS/83 was used as the system language in this study, system development with some other language is also possible. Specific knowledge on the planning and scheduling of construction operations can also be incorporated in advance into the system as rules. For these reasons, simulation using this methodology will conceivably make it possible not only to estimate the productivity of work and the state of progress, but also to optimize the construction plan and its alternatives.

\footnotetext{
1) A. A.B. Pristker. "GERT Graphical Evaluation and Review Technique", Memorandun RM-4973-NASA, 1966.04, KAND

2) D.W.Halpin, W.W. Happ, "Network Simulation of Construction operations", proc of 3 rd Internet-72, Stockholm. Sweden, 1972.05

3) A. Anthony, "INSIGHT Interactive Simulation of Construction operations Using Graphical Techniques", Tech.Report 238, 1980, Department of Civil Engineering. St anford University

4) Tetuo Kanaiwa. "Development of Simulation Model(SIMUCO) for Construction Operations". Annual Sympo. of AIJ, 1981.09

5) Yasushi Tamura, Naruo Kano, "Development of Construction Simulation System GRAPSS" Annual Sympo, of AIJ,1976,07

6) Naruo Kano. "An Expert System for Construction Planning",5th International Sympo. on Robotics in Construction, Tokyo, Japan, 1988.06 7) C.L.Forgy,"OPS/83 User's Manual and Report.1985.12.PST Inc. 8) Naruo Kano, "Simulation Methodology in Construction Process",3rd International sympo. of Robotics in Building Construction, Marseilles, France. 1986.06
} 